\title{
Morning glory syndrome: clinical and electrofunctional study of three cases
}

\author{
GIUSEPPE GIUFFRE \\ From the Istituto di Clinica Oculistica, Università di Palermo, Italy
}

SUMMARY Three cases of morning glory syndrome are described and some new electrofunctional and tomodensitometric findings are reported. The amplitude of the waves of the electroretinogram is reduced and correlates with the extension of the retinal changes. The visually evoked potentials elicited with bright flashes have normal latencies but generally subnormal amplitudes. The amplitude of the potentials probably depends on the degree of involvement of the optic nerve. The computerised tomography performed in one patient disclosed undescribed changes in the retrobulbar optic nerve.

The term morning glory syndrome was given by Kindler' in 1970 to a rare ocular anomaly characterised by a large staphylomatous optic disc covered by glial tissue. The peripapillary area is occupied by a ring of pigmentary abnormality and crossed by anomalous retinal vessels.

During the last few years many cases of morning glory syndrome have been described. These reports have contributed to the clarification of various clinical $^{2-4}$ pathogenetical, ${ }^{5-7}$ and pathological ${ }^{7}$ problems of the disease. The electrophysiological features, however, have not been extensively investigated. For this reason we are reporting three new cases of morning glory syndrome studied particularly from the electrofunctional point of view.

\section{Materials and methods}

The electroretinogram was recorded after dilatation of the pupils with $0.5 \%$ tropicamide and $10 \%$ phenylephrine. The active electrode was a BurianAllen silver electrode; the indifferent electrode was placed on the eyebrow and the ground in the centre of the forehead. The scotopic electroretinogram was recorded after 15 minutes of dark adaptation. The stimulation was a single flash of white light emitted by a photostimulator placed $33 \mathrm{~cm}$ away from the patient's forehead. The intensity of stimulation was of $0.3 \mathrm{Joule} / \mathrm{flash}$. This intensity was attenuated by

Correspondence to Dr Giuseppe Giuffrè, Istituto di Clinica Oculistica, Via L Giuffrè 13, 90127 Palermo, Italy. the use of neutral density filters of 3 and 2 logarithmic units. The photopic electroretinogram was recorded after 5 minutes of light adaptation at 1000 lux. The frequency of stimulation was 20 and 50 flashes/second with light intensity of 0.2 Joule. The signals were led to an OTE Biomedica preamplifier Model 1076 with a time constant of 0.3 second. For the photopic electroretinogram 64 responses were averaged by an OTE Biomedica neuroaveraged Model 1172. The responses were written by an $\mathrm{X}-\mathrm{Y}$ recorder OTE Biomedica Model 1013.

The visually evoked potentials were recorded in mesopic adaptation and mydriasis with a needle electrode inserted $2.5 \mathrm{~cm}$ above the inion. The indifferent electrode was placed on the vertex; the ear lobe was earthed. The stimuli were flashes of white light emitted by a photostimulator placed $33 \mathrm{~cm}$ away from the patient, the intensity being 0.3 Joule and the frequency 1 per second, and flashes of sinusoidal light with frequency of 10 and 20 per second. The responses were amplified, and the time constant was of 0.7 second. For each stimulus $80-100$ responses were evoked that were subsequently averaged and recorded.

The Kowa $\mathrm{RC}-\mathrm{xV}$ retinograph was employed to take the fundus photographs and the fluorescein angiography after the injection of $5 \mathrm{ml}$ of $10 \%$ sodium fluorescein into a superficial vein of the forearm. The visual field was checked with the Goldmann perimeter. The colour sense was tested with the pseudoisochromatic tables of Ishihara. 


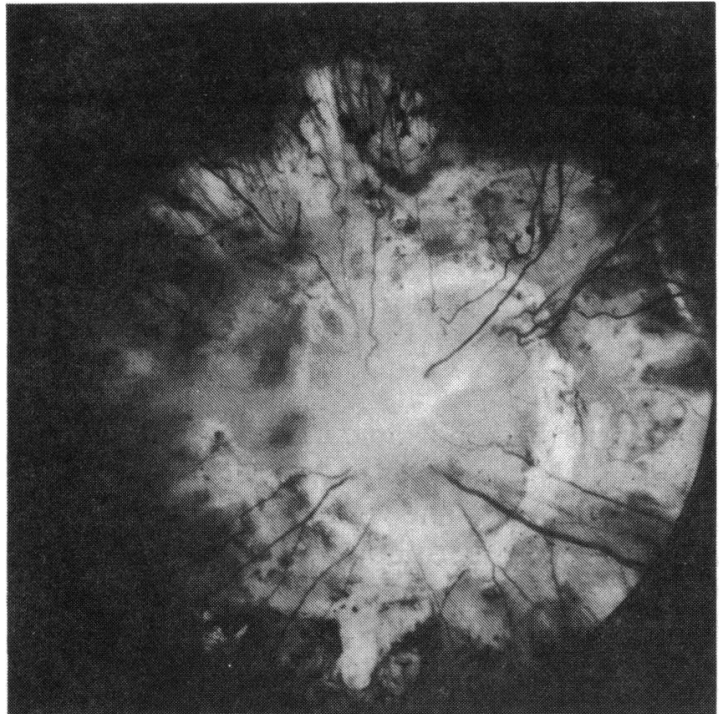

Fig. 1 Case 1. Fundus photograph of the left eye showing an enlarged and staphylomatous optic disc covered by a mass of greyish tissue and surrounded by a ring of retinochoroidal atrophy.

\section{Case reports}

\section{CASE 1}

A 31-year-old man was referred to our clinic with a diagnosis of coloboma of the optic nerve in the left eye. He had never seen well with this eye. Corrected visual acuity was $20 / 20$ in the right eye with sph +2.00 and uncertain light perception in the left eye. The refractive error in the left eye was of -2.50 dioptres. The right pupil was normally responsive to light. The left pupil had a diameter of $3 \mathrm{~mm}$ and an afferent pupillary defect. The left eye had exotropia of 45 prism dioptres and pendular nystagmus. The ocular adnexa, the anterior segment, the vitreous, and the intraocular pressure were normal.

The right fundus showed optic disc pallor with superior and inferior arcuate nerve fibre bundle defects. In the left eye the optic disc was enlarged, staphylomatous, and partly covered by a mass of greyish tissue (Fig. 1). From the centre of the disc arose a number of straight and thin retinal vessels. The optic nerve head was surrounded by a large area of retinochoroidal atrophy speckled by small amounts of pigment. Below the disc there was a small retinochoroidal coloboma. The macula was unrecognisable.

Fluorescein angiography gave normal results in the right eye and in the left showed early visualisation of the choroidal vessels due to the atrophy of the peripapillary pigment epithelium. The filling of the retinal arteries and veins was delayed. Some vessels showed a tortuous course and loops, and some

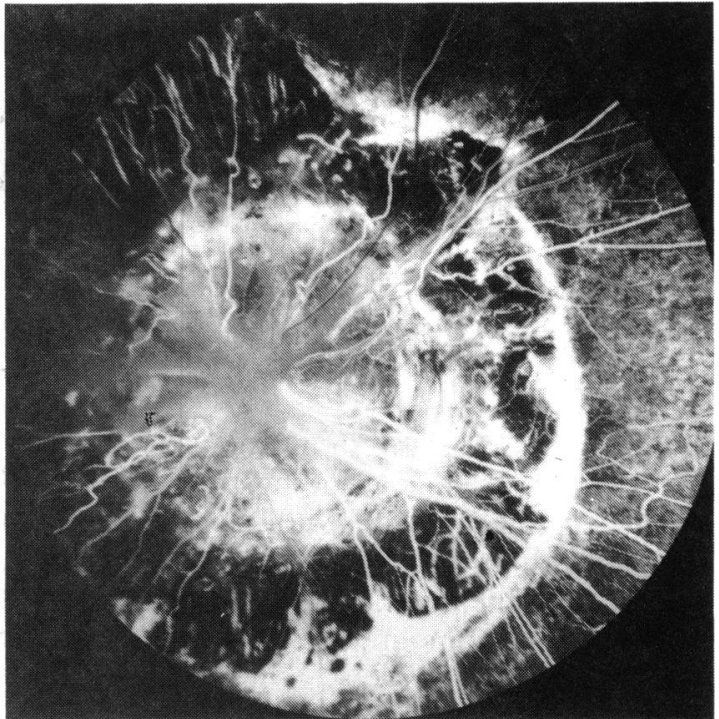

Fig. 2 Case 1. Fluorescein angiography of the left eye, early venous phase. The vessels on the disc appear anomalous and the filling of the venules is delayed ( 25 seconds). Temporally to the disc the macula is unrecognisable.

leakage was observed (Fig. 2). In the late venous phase the walls of the staphyloma became hyperfluorescent (Fig. 3).

Goldmann visual field revealed a nasal hemianopia in the right eye (Fig. 4). This defect was identical to the one found in an earlier examination made six

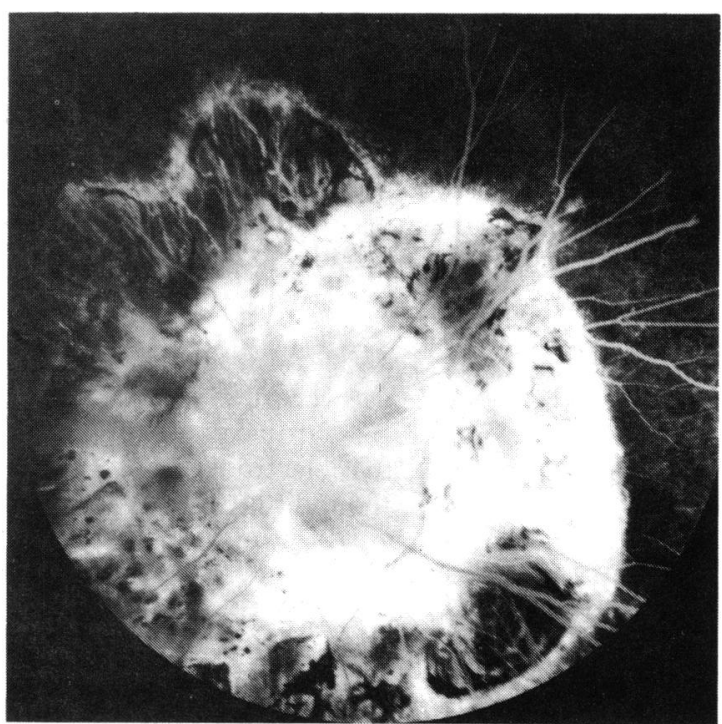

Fig. 3 Case 1. Fluorescein angiography of the left eye, late venous phase. The peripapillary area and the walls of the staphyloma are hyperfluorescent. 


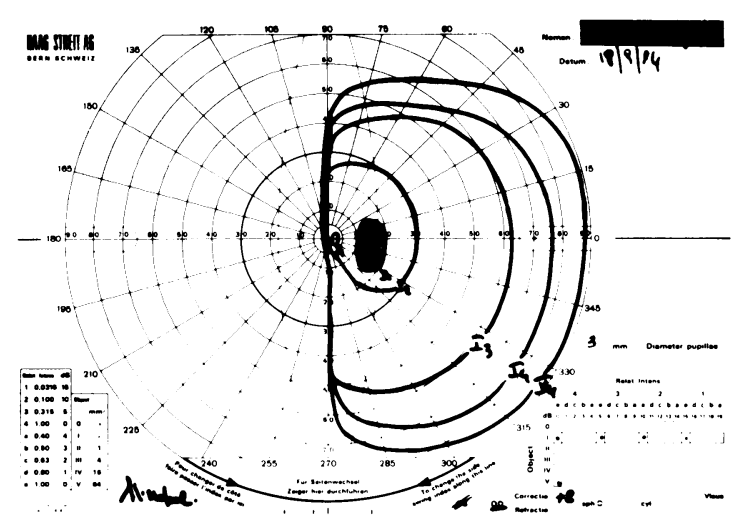

Fig. 4 Case 1. The visual field of the right eye shows a nasal hemianopia.

years before. The visual field of the left eye was impossible to chart, but the patient seemed to perceive faintly the target $\mathrm{V}_{4}$ from the nasal side. Colour sense was normal in the right eye and not recordable in the left eye.

The electroretinogram and the visually evoked potentials were unremarkable in the right eye. In the scotopic electroretinogram of the left eye the amplitudes of the a and particularly of the $b$ waves were subnormal (Fig. 5). The implicit times were normal.
The amplitude of the photopic electroretinogram was also pathologically reduced. The visually evoked potentials elicited at $1 \mathrm{~Hz}$ had a borderline latency and amplitude. At higher frequencies the amplitude of the potentials was frankly abnormal (Fig. 5). The electrofunctional responses of the three patients with morning glory syndrome are summarised in Table 1.

Computerised tomography with contrast of the left orbit showed a high density intrabulbar optic nerve. The retrobulbar optic nerve was thickened (Fig. 6). The peripheral portion of the nerve was hypodense and a core of hypodensity was present in a long tract of the nerve (Fig. 7). Cerebral CT showed porencephaly of the right parieto-occipital lobe.

\section{CASE 2}

This 21-year-old man complained of very low visual acuity in his right eye since birth. The visual acuity was $2 / 200$ in the right eye and $20 / 20$ in the left eye with sph -1.00 cyl -1.00 ax $90^{\circ}$. In the right eye the refraction was of sph $-3.50 \mathrm{cyl}-1.25 \mathrm{ax} 90^{\circ}$. There was a marked afferent pupillary defect in the right eye. Ocular motility, anterior segment, lens, and vitreous were normal in both eyes.

Fundus examination of the right eye showed a large and excavated disc surmounted by a tuft of white matter hiding the origin of the retinal vessels. These vessels were numerous, straight, and of

\section{Scotopic ERG}

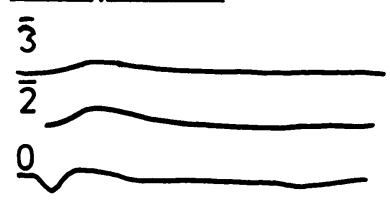

\section{Photopic ERG}

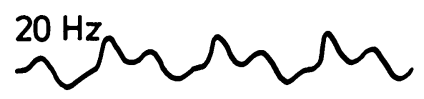

\section{$50 \mathrm{~Hz}$}
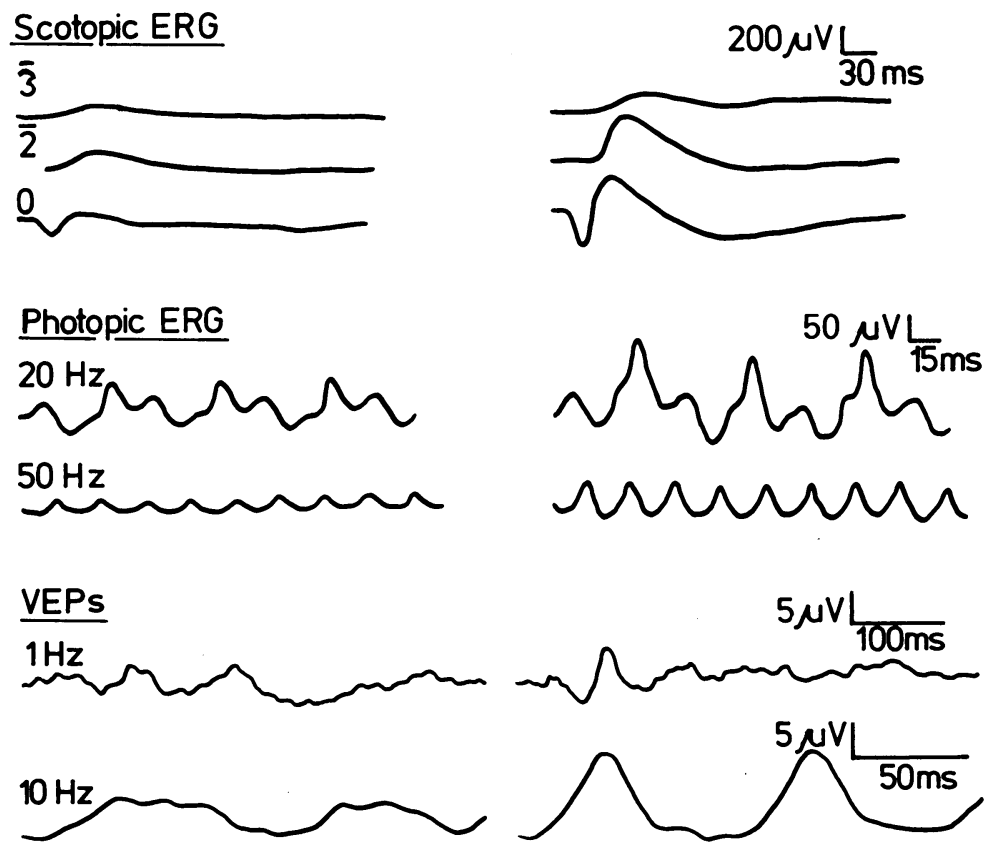

$20 \mathrm{~Hz}$

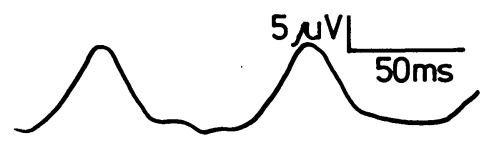

Fig. 5 The electroretinogram and the visually evoked potentials of the left eye of patient 1 (on left) compared with the responses of $a$ normal subject (on right). 
Table 1 Summary of the electroretinograms and the visually evoked potentials

\begin{tabular}{|c|c|c|c|c|c|c|c|c|}
\hline \multicolumn{9}{|c|}{ Electroretinogram } \\
\hline & \multirow{2}{*}{$\begin{array}{l}\text { Scotopic } 3 \\
\text { b Wave } \\
\text { amplitude }\end{array}$} & \multirow{2}{*}{$\begin{array}{l}\text { Scotopic } 2 \\
\begin{array}{l}\text { b Wave } \\
\text { amplitude }\end{array}\end{array}$} & \multicolumn{2}{|l|}{ Scotopic 0} & \multicolumn{2}{|l|}{ Scotopic 0} & \multirow{2}{*}{$\frac{\text { Photopic } 20}{\text { Amplitude }}$} & \multirow{2}{*}{$\frac{\text { Photopic } 50}{\text { Amplitude }}$} \\
\hline & & & $\begin{array}{l}\text { a Wave } \\
\text { amplitude }\end{array}$ & $\begin{array}{l}\text { b Wave } \\
\text { amplitude }\end{array}$ & $\begin{array}{l}\text { a Wave } \\
\text { implicit time }\end{array}$ & $\begin{array}{l}b \text { Wave } \\
\text { implicit time }\end{array}$ & & \\
\hline $\begin{array}{l}\text { Case } 1 \\
\text { Case } 2 \\
\text { Case } 3 \\
\text { Normal }\end{array}$ & $\begin{array}{l}57 \mu V \\
87 \mu V \\
50 \mu V \\
132 \pm 43 \mu V\end{array}$ & $\begin{array}{l}125 \mu \mathrm{V} \\
200 \mu \mathrm{V} \\
137 \mu \mathrm{V} \\
330 \pm 72 \mu \mathrm{V}\end{array}$ & $\begin{array}{l}125 \mu \mathrm{V} \\
175 \mu \mathrm{V} \\
150 \mu \mathrm{V} \\
265 \pm 63 \mu \mathrm{V}\end{array}$ & $\begin{array}{c}37 \mu \mathrm{V} \\
125 \mu \mathrm{V} \\
137 \mu \mathrm{V} \\
226 \pm 55 \mu \mathrm{V}\end{array}$ & $\begin{array}{l}38 \mathrm{~ms} \\
34 \mathrm{~ms} \\
38 \mathrm{~ms} \\
34 \cdot 6+2 \cdot 5 \mathrm{~ms}\end{array}$ & $\begin{array}{l}69 \mathrm{~ms} \\
65 \mathrm{~ms} \\
67 \mathrm{~ms} \\
64 \cdot 9+4 \cdot 5 \mathrm{~ms}\end{array}$ & $\begin{array}{l}90 \mu \mathrm{V} \\
119 \mu \mathrm{V} \\
162 \mu \mathrm{V} \\
171 \pm 25 \mu \mathrm{V}\end{array}$ & $\begin{array}{l}28 \mu V \\
41 \mu V \\
25 \mu V \\
72 \pm 19 \mu V\end{array}$ \\
\hline \multicolumn{9}{|c|}{ Visual evoked potentials } \\
\hline & \multicolumn{2}{|l|}{$1 \mathrm{~Hz}$} & \multicolumn{2}{|l|}{$l \mathrm{~Hz}$} & \multicolumn{2}{|l|}{$10 \mathrm{~Hz}$} & $20 \mathrm{~Hz}$ & \\
\hline & \multicolumn{2}{|c|}{ Wave amplitude } & \multicolumn{2}{|l|}{ Wave latency } & \multicolumn{2}{|l|}{ Amplitude } & \multicolumn{2}{|l|}{ Amplitude } \\
\hline $\begin{array}{l}\text { Case } 1 \\
\text { Case } 2 \\
\text { Case } 3 \\
\text { Normal }\end{array}$ & $\begin{array}{l}4.5 \mu \mathrm{V} \\
- \\
7 \cdot 5 \mu \mathrm{V} \\
8 \cdot 3 \pm 2 \cdot 5 \mu \mathrm{V}\end{array}$ & & $\begin{array}{l}114 \mathrm{~ms} \\
\overline{104} \mathrm{~ms} \\
101+11.7 \mathrm{~ms}\end{array}$ & & $\begin{array}{l}5 \cdot 75 \mu \mathrm{V} \\
4 \cdot 5 \mu \mathrm{V} \\
11 \mu \mathrm{V} \\
12 \cdot 9 \pm 3 \cdot 1 \mu \mathrm{V}\end{array}$ & & $\begin{array}{l}1.5 \mu \mathrm{V} \\
1.75 \mu \mathrm{V} \\
- \\
6.8 \pm 1.7 \mu \mathrm{V}\end{array}$ & \\
\hline
\end{tabular}

uniform calibre (Fig. 8). A prominent ring of pigmentary changes occupied the peripapillary area. The macula was hypoplasic and without reflex. The fundus of the left eye was normal.

In fluorescein angiography the retinal arteries were filled about 2 seconds after the choroidal arteries visible through the peripapillary pigment defect. The epipapillary glial mass caused a masking hypofluorescence of the optic disc. The retinal veins were filled 8

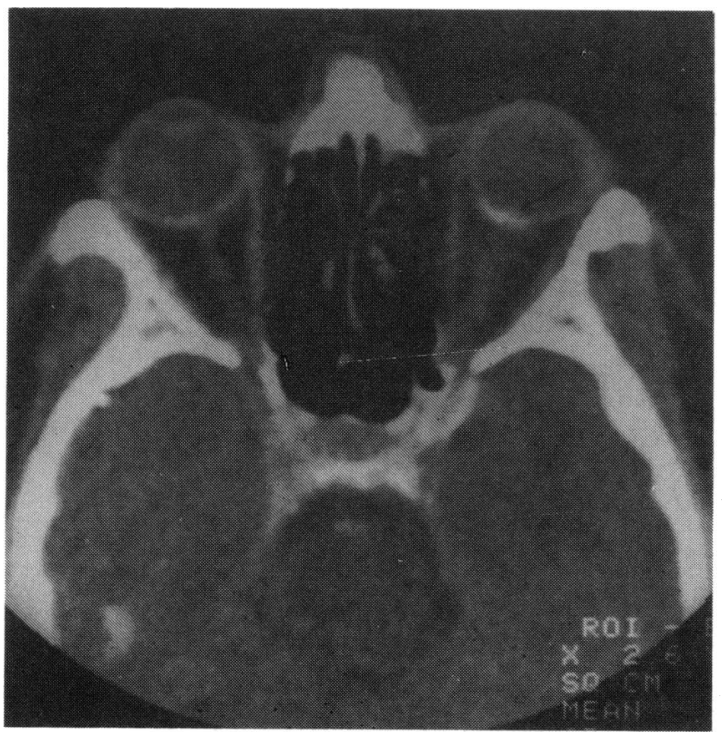

Fig. 6 Case 1. Computerised tomography, sagittal view. The left intrabulbar optic nerve is hyperdense (arrow), and the retrobulbar nerve appears enlarged. seconds after the arteries. In the late angiograms the peripapillary area and the walls of the staphyloma were slightly hyperfluorescent. The retinal vessels never leaked fluorescein (Fig. 9).

The visual field of the right eye delineated a dense central scotoma. None of the Ishihara tables were recognised in this eye.

The amplitudes of the waves of the scotopic and the photopic electroretinogram were subnormal in

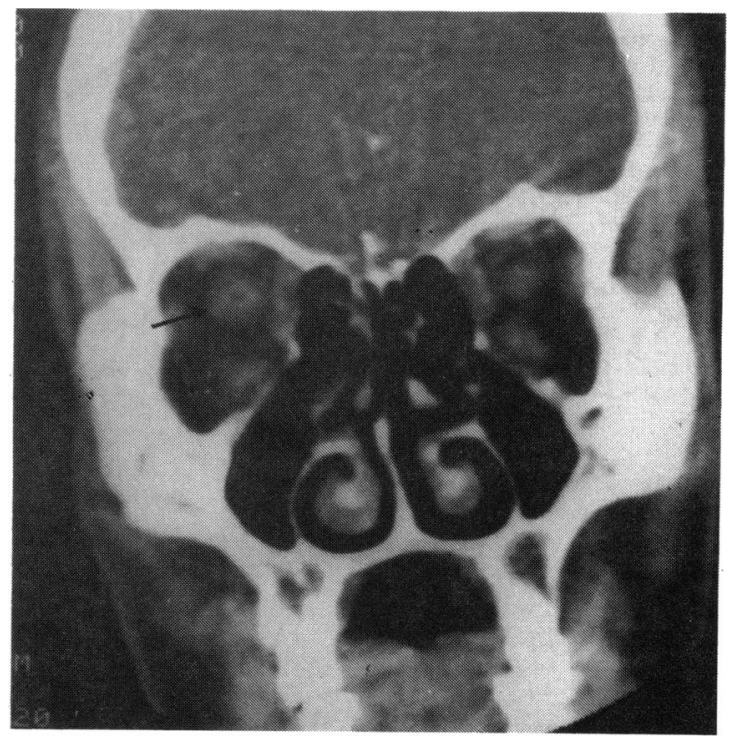

Fig. 7 Case 1. Computerised tomography, coronal view. Delineates hypodense areas around and inside the left retrobulbar optic nerve (arrow). 


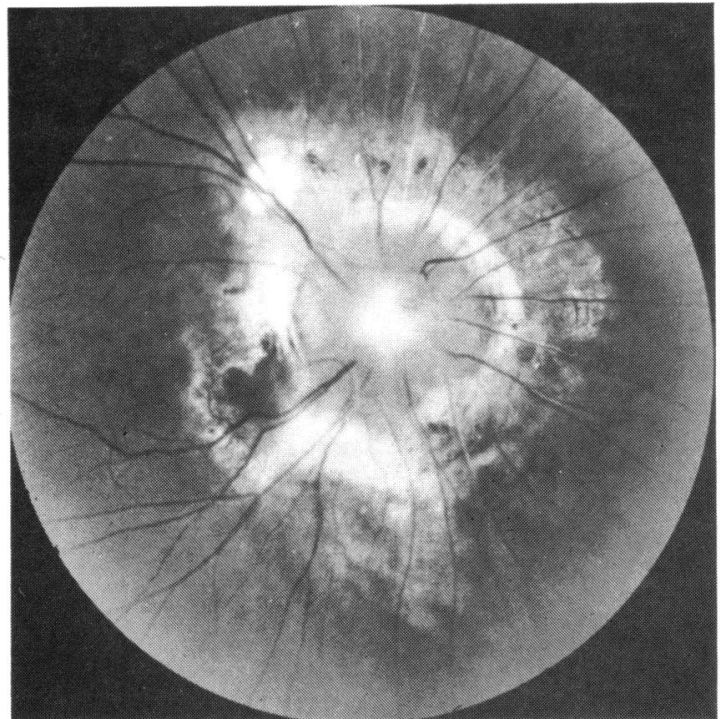

Fig. 8 Case 2. Fundus photograph of the right eye. The disc is enlarged and surmounted by a tuft of glial tissue. The retinal arteries are straight and sheathed.

the right eye (Fig. 10). This amplitude reduction involved the a as well as the $b$ wave. The implicit times were normal. It was not possible to record visually evoked potentials at $1 \mathrm{~Hz}$. At 10 and $20 \mathrm{~Hz}$ the potentials had very low amplitudes (Fig. 10). In the left eye the electroretinogram and the visually evoked potentials had normal values.

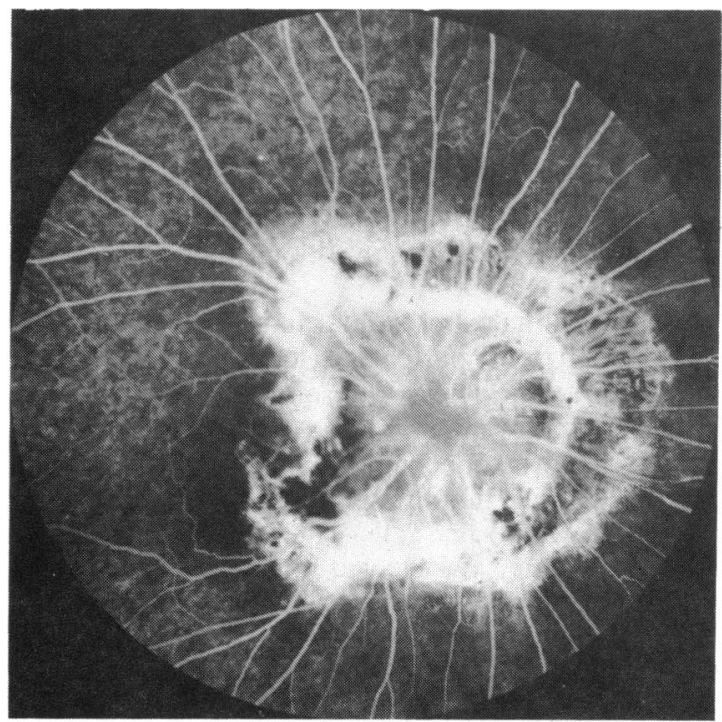

Fig. 9 Case 2. Fluorescein angiography, late venous phase. The anomalous vessels do not leak dye. The fovea is barely recognisable and partly covered by the ring of pigmentary changes.
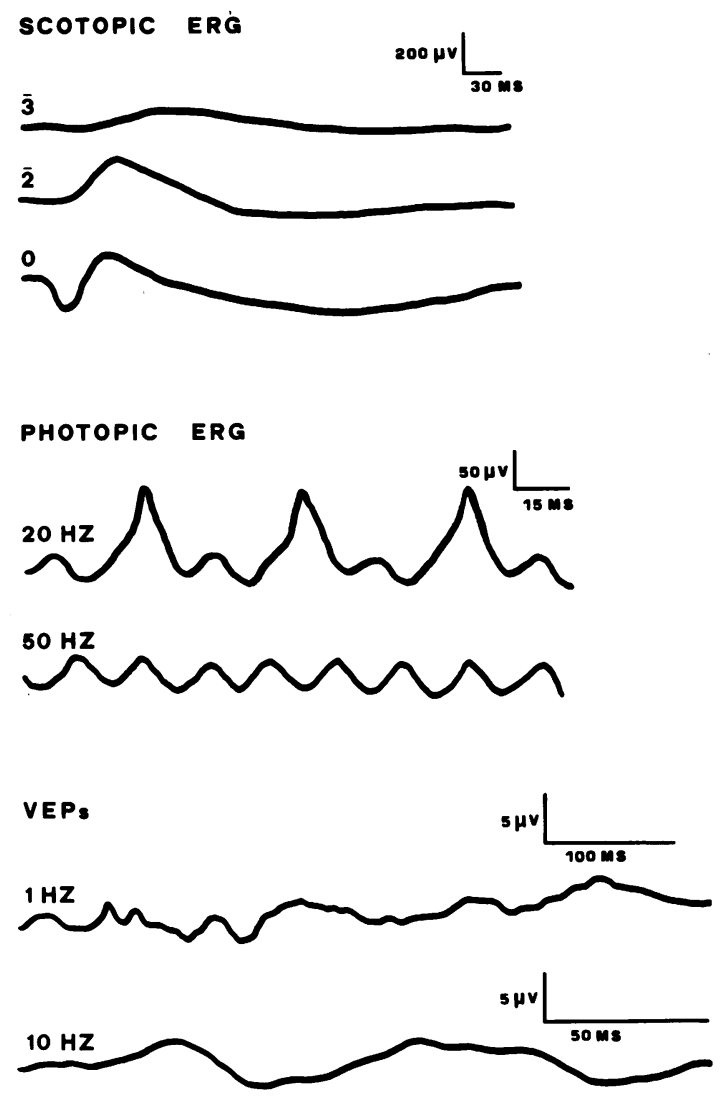

$20 \mathrm{HZ}$

Fig. 10 Case 2. Electroretinogram and visually evoked potentials of the right eye.

CASE 3

A woman of 73 years was referred to us to have her cataracts examined. She had had no previous ocular troubles and remembered that she could see well with both eyes when she was young. She suffered from slight diabetes. Her visual acuity was 20/400 in the right eye and 20/200 in the left eye with cyl -1.00 ax $90^{\circ}$. The right eye was emmetropic. Pupillary responses were normally present in both eyes. Examination of extrinsic motility disclosed a slight hypofunction of the superior oblique of the left eye. There were bilateral nuclear cataracts.

In the right eye the optic disc was slightly enlarged and staphylomatous and a white spot of tissue of glial appearance lay in its centre. The retinal vessels had a straight course at the origin but were easily distinguishable in arteries and veins. A wide pigmentary defect surrounded the disc. The macula appeared normal (Fig. 11). The fundus of the left eye showed 


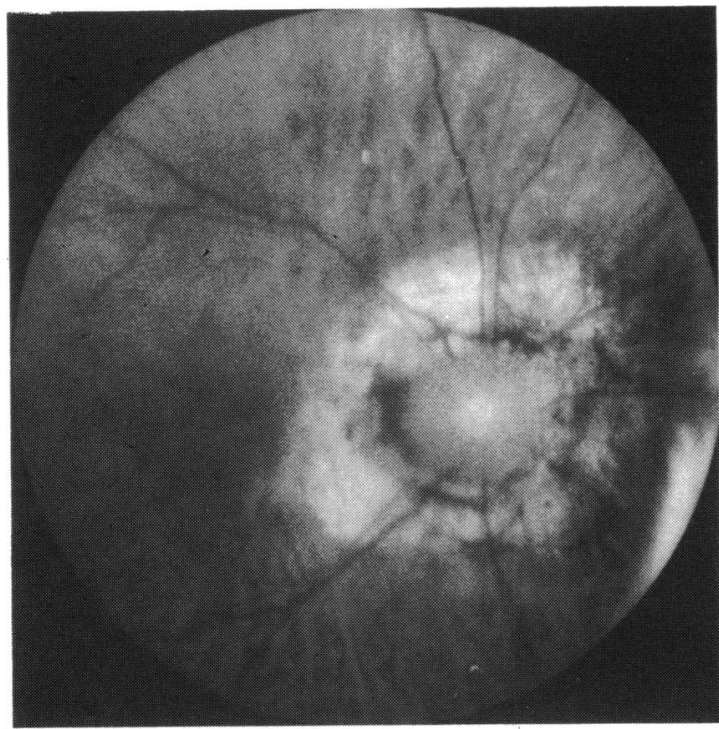

Fig. 11 Case 3. Fundus photograph of the right eye showing a slightly enlarged optic disc with a peripapillary ring of pigment atrophy. The arteries are easily distinguishable from the veins. The low quality of the photograph is due to the cataract.

only a diffuse senile atrophy of the retinal pigment epithelium.

In fluorescein angiography the peripapillary atrophic area had been hypofluorescent from the early phase. The filling of the retinal vessels was

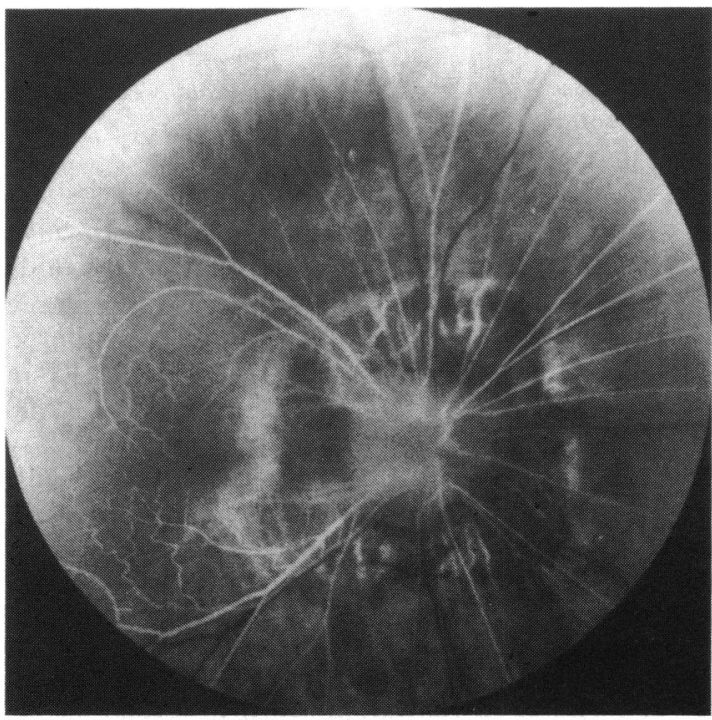

Fig. 12 Case 3. Fluorescein angiography, early venous phase. The choroidal vessels are visible through the peripapillary defect. The filling of the veins is delayed (18 seconds). The macular area is well delineated.

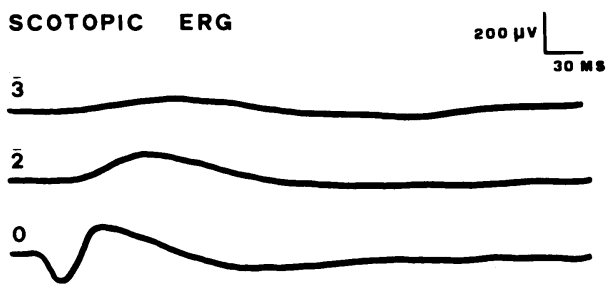

PHOTOPIC ERG

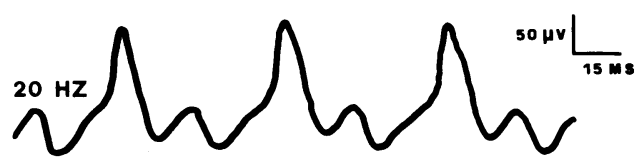

$50 \mathrm{HZ}$
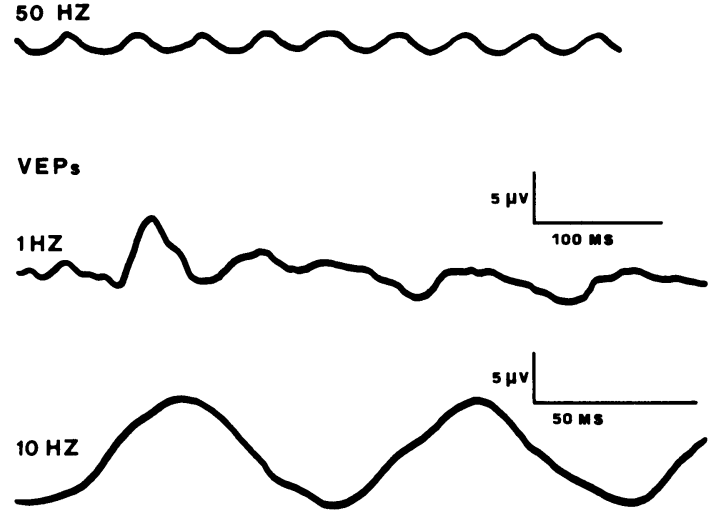

$20 \mathrm{HZ}$

Fig. 13 Case 3. Electroretinogram and visually evoked potentials of the right eye.

delayed. The macula showed a normal fluorescence (Fig. 12).

The visual field was similar in both eyes, showing constriction of the peripheral isoptres and absence of the central ones. The colour sense was normal.

In the right eye the scotopic and photopic electroretinogram was subnormal with almost all the stimuli (Fig. 13). The amplitude of the visually evoked potentials was normal at least at low frequencies (Fig. 13). The latency at $1 \mathrm{~Hz}$ was normal. In the left eye the electroretinogram was at low limits; the visually evoked potentials were normal.

\section{Discussion}

The ophthalmological features of the morning glory syndrome are well known. ${ }^{1 \times 4}$ The enlarged optic disc lies in the centre of a staphyloma involving the nerve 
and the peripapillary area of the globe, so that the region assumes a funnel-shaped appearance. Glial proliferation on the disc can be considerable and cause progressive elevation of the optic nerve head. In the peripapillary area a ring of pigmentary disturbance is almost constant. The retinal vessels arising from the optic disc are numerous, straight, and hardly distinguishable between arteries and veins.

The cases reported here show all these features to a different extent. In the first patient the disc is much enlarged, but in the third case it is of an almost normal dimension. Gliosis is remarkable in the first case, where it spreads in finger-like projections towards the retina. There are atrophic peripapillary pigmentary changes in all cases, while there is little hyperplasia. The retinal vessels are very anomalous and rich in loops in the first case, but far less abnormal in the third.

Macular abnormalities are frequent in the morning glory syndrome. Sometimes the foveal reflex is lacking and a yellowish retinal area temporal to the peripapillary ring represents an abnormally developed macula. ${ }^{3}$ At other times the macula shows a normal development, and a satisfactory visual acuity can be recorded." In case 1 a structure similar to the macula is lacking, while it is present but rudimentary in case 2 , where the macula appears somewhat pigmented, stretched towards the disc, and without a foveal reflex. In case 3 the macula is normal, and it is probable that the low visual acuity is due more to the cataract than to the fundal anomaly.

Orbital computerised tomography of the only patient in which this examination was performed showed undescribed findings. In the previous tomodensitometric reports of the morning glory syndrome the retrobulbar optic nerve was normal except at its distal end, where the staphyloma could be delineated. ${ }^{271112}$ In our case the retrobulbar part of the nerve was thickened: a hypodense sheath surrounded the nerve proper and a hypodense core was encased axially in the optic nerve. Several pathological studies showed that the retrobulbar optic nerve is highly abnormal in the morning glory syndrome. The nerve is atrophic and the meningeal sheaths are replaced by fibrous and fatty tissue.$^{73}$ In particular, the pathological specimen from case 2 described by Apple et al..$^{14}$ evokes the tomodensitometric picture reported here: the optic nerve showed a perineural sheath of adipose tissue, and foci of adipose tissue were located centrally in the nerve. Thus the hypodense matter located inside and around the optic nerve in our case might be adipose tissue migrated into the optic nerve through the embryonic fissure ${ }^{15}$ or produced by adipose metaplasia of the perioptic tissues. ${ }^{14}$

In case 1 there is a nasal hemianopia in the visual field of the contralateral eye. The defect was probably congenital and was unchanged after a lapse of six years. It was caused by the porencephaly of the ipsilateral posterior cerebral hemisphere. The optic atrophy and the nerve fibre bundle defects of the right eye were produced by the transsynaptic degeneration of the pregeniculate pathway.

In patients with morning glory syndrome many anomalies have been described in the involved eye, such as ciliary body cyst,' congenital cataract, ${ }^{16}$ persistent pupillary membrane,$^{16}$ and vitreous cyst ${ }^{9}$; in the contralateral eye, congenital cataract, ${ }^{\prime}$ anterior chamber cleavage syndrome, ${ }^{1}$ microcornea,${ }^{16}$ and Duane's retraction syndrome ${ }^{17}$; and in other systems, cleft palate and basal encephalocele,,$^{18} 19$ renal hypoplasia, ${ }^{20}$ and somatic anomalies due to breaks of chromosomes. ${ }^{2}$ Thus the morning glory syndrome may represent more than a simple optic nerve anomaly, a disembryogenetic disease with the involvement of various organs.

The electrofunctional findings of the morning glory syndrome are not well known. In one case of the syndrome with cataract $^{21}$ the photopic electroretinogram was present, but the waves were less wide than controlaterally. The visually evoked potentials showed waves of little amplitude and badly individualised. In another study carried out in an eye with morning glory syndrome and without light perception" the amplitude of the $a$ and $b$ wave of the electroretinogram was subnormal and the visually evoked potentials unrecordable.

The electroretinographic responses obtained from our patients confirm the scanty data of the literature. In all our three cases we recorded an electroretinogram of reduced amplitude. This abnormality concerns above all the $b$ wave, and it is generally proportional to the retinal damage ophthalmoscopically visible. Histopathological studies performed on eyes affected by morning glory syndrome have shown that the retina is much involved. There is attenuation of the outer nuclear layer together with a localised absence of the visual cells, ${ }^{22}$ extensive areas of necrosis and cellular infiltration in the outer retinal layers, ${ }^{13}$ and glial cells replacing the ganglion cell layer.?

Such changes are prominent in a more or less wide peripapillary area. The rest of the retina may show some generalised atrophy, but the retinal layers appear to be normally formed and clearly recognisable. These facts well explain the electroretinographic findings-that is, the reduced amplitude of the waves and the normal implicit times. In fact amplitude and implicit time behave independently of one another in the localised diseases of the retina. ${ }^{23}$ In these cases the amplitude is reduced because of the focal compromise of the retinal cells, but the implicit 
time is normal owing to the normal transmission of the nervous impulse in the remaining healthy retina.

The visually evoked potentials are generally recordable but of subnormal amplitude in congenital anomalies of the optic disc. ${ }^{24}$ The latency is usually normal. Our findings on patients with morning glory syndrome agree with the ones on patients with other anomalies of the optic disc. It was possible to elicite visually evoked potentials in all the patients, including the one with uncertain light perception. The amplitude of the potentials is much reduced in two cases, and it probably depends on the large reduction of fibres in the optic nerve. The axons may be almost totally replaced by glial cells, fibrosis, and calcifications. ${ }^{72}$ Possible macular abnormalities may contribute to the reduced amplitude of the waves. The temporal components of the visual potentials were normal in all the cases in which a readable recording was obtained. Finally it should be emphasised that some of the abnormalities of the visually evoked potentials may arise from the strabismic amblyopia developing precociously in many cases of morning glory syndrome.

\section{References}

1 Kindler P. Morning glory syndrome: unusual congenital optic disk anomaly. Am J Ophthalmol 1970; 69: 376-84.

2 Beyer WB, Quencer RM, Osher RH. Morning glory syndrome. A functional analysis including fluoresccin angiography, ultrasonography, and computerized tomography. Ophthalmology (Rochester) 1982; 89: 1362-7.

3 Yamana T, Nishimura M, Ueda K, Chijiiwa T. Macular involvement in morning glory syndrome. Jpn J Ophthalmol 1983; 27: 201-9.

4 Cennamo G, Sammartino A, Fioretti F. Morning glory syndrome with contractile peripapillary staphyloma. $\mathrm{Br} J \mathrm{Oph}$ thalmol 1983; 67: 346-8.

5 Brini A, Charton MN, Baumgartner M. Staphylome scléral péripapillaire avec ectopie postérieure de la papille (morning glory syndrome). J Fr Ophthalmol 1980; 3: 323-6.

6 Apple J. Pathologie des Nervus opticus unter besonderer Berücksichtigung kolobomatöser Anomalien. Fortschr Ophthalmol 1983; 80: 19-25.
7 Dempster AG, Lee WR, Forrester JV, McCreath GT. The 'morning glory syndrome' - a mesodermal defect? Ophthalmologica 1983 ; 187: 222-30.

8 Krause U. Three cases of the morning glory syndrome. Acta Ophthalmol (KGL) 1972; 50: 188-98.

9 Steinkuller PG. The morning glory disk anomaly: case report and literature review. J Pediatr Ophthalmol Strabismus 1980; 17: 81-7.

10 Hamada S, Inoue Y, Matsuda K. A case of morning glory syndrome with good visual acuity. Jpn J Ophthalmol 1978; 32: 196-7.

11 Le Rebeller MJ. Tomodensitométric en pathologie oculo orbitaire: scanographic et oeil. Bull Soc Ophtalmol Fr 1982; Novembre numéro special: 195-227.

12 Adam P, Bec P, Mathis A, Alberge Y. Morning glory syndrome: CT findings. J Comput Assist Tomogr 1984; 8: 134-6.

13 Font RL, Zimmerman LE. Intrascleral smooth muscle in coloboma of the optic disk. Electron microscopic verification. Am J Ophthalmol 1971; 72: 452-7.

14 Apple DJ, Dagher CY, Shammas HF, Miller K. Anomalous intraocular and periocular formation of adipose tissue. Am J Ophthalmol 1982; 94: 344-50.

15 Barber AN. Embryology of the human eye. London: Kimpton, 1955.

16 Odagiri Y, Ito $\mathrm{T}$. The morning glory syndrome. Jpn J Clin Ophthalmol 1975; 29: 481-8.

17 Kawano K, Fujita S. Duane's retraction syndrome associated with morning glory syndrome. J Pediatr Ophthalmol Strabismus 1981; 18: 51-4.

18 Pollock JA, Newton TH, Hoyt WF. Transsphenoidal and transethmoidal encephaloceles. Radiology 1968; 90: 442-53.

19 Caprioli J, Lesser RL. Basal encephalocele and morning glory syndrome. BrJ Ophthalmol 1983; 67: 349-51.

20 Rieger G. Zum Krankheitsbild der Handmannschen Sehnervenanomalie. Winderbluten (morning glory) Syndrom? Klin Monatsbl Augenheilkd 1977; 170: 697-706.

21 Poletti J, Leleux D, Henry J. A propos d'une association morning glory syndrome-cataractc. Bull Soc Ophtalmol Fr 1982; 82: $1463-5$.

22 Pedler C. Unusual coloboma of the optic nerve entrance. Br J Ophthalmol 1961; 45: 803-7.

23 Berson EL, Gouras P, Hoff M. Temporal aspects of the clectroretinogram. Arch Ophthalmol 1969; 81: 207-14.

24 Babel J, Stangos N, Korol S, Spiritus M. Ocular electrophysiology. Stuttgart: Thieme, 1977.

25 Willis R, Zimmerman LE, O’Grady R, Smith RS, Crawford B. Heterotopic adipose tissue and smooth muscle at the optic disc. Arch Ophthalmol 1972; 88: 139-46.

Accepted for publication 19 July 1985. 